Inonu University Journal of Art and Design (2019) SSN: 309-9876, E-ISSN: 1309-9884

Available online at http://dergipark.gov.tr/iujad

Inonu University Journal of Art and Design

Faculty Homepage: http://www.inonu.edu.tr/tr/gsf

Korunan Alanların Ziyaretçi Yönetiminde Normatif Yaklaşım

Normative Approach in Visitor Management of Protected Areas

Meryem Bihter BİNGÜL $a, *$ iD

a Doktor Öğretim Üyesi, Iğdır Üniversitesi, Ziraat Fakültesi, Peyzaj Mimarlığı Bölümü, Iğdır, 76000, TR

Article history: Received 01-07-2019 / Accepted 30-12-2019

\title{
ÖZET ABSTRACT
}

Korunan alanlarda ziyaretçi sayılarının sürekli artması ile birlikte ziyaretçi faaliyetlerinin neden olduğu etkilerin tespit edilmesi ve yönetilmesi giderek zorlaşmaktadır. Bu durum alan yöneticilerinin karar verme süreçlerini de etkilemekte ve sürdürülebilir yönetimi karmaşık hale getirmektedir. Normatif yaklaşım rekreasyonel faaliyetlerin gerçekleştiği bu alanlarda kaynak değerlerin ve kullanıcı deneyim kalitesini arttırmak ve aynı zamanda alan yönetimine yardımcı olmak amacıyla sosyal bilimler disiplinlerinden doğal kaynak yönetime uyarlanmış bir yaklaşımdır. Normlar, insanların davranışlarını veya davranışlarının sonucu olarak ortaya çıkan sonuçlar kabul edilebilir veya kabul edilemez olarak değerlendirmek için kullandıkları standartlardır. Normlar bu nedenle hangi davranışın veya koşulların olmas gerektiğini tanımlayarak yöneticilere yönetim kararların düzenlemede yardımcı olur. Bu çalışmada, ziyaretçi yönetimi çalışmalarında yer alan normatif yaklaşım ve bu bağlamda, norm kavramı, normların nasıl ölçüldüğü ve ziyaretçi yönetiminde nasıl yer bulduğu incelenmiştir.

Anahtar Kelimeler: Korunan Alanlar, Ziyaretçi Yönetimi, Normatif Teori, Standartlar, Normların
In protected areas, it is becoming more difficult to identify and manage the impacts of visitor activities due to a constantly increasing number of visitors. This also affects the decision-making process of land managers and complicates sustainable management. Normative approach is an approach that adapted from social science disciplines to natural resources in order to increase resource values and quality of user experience in these areas where recreational activities take place and at the same time to help the land management process. Norms are the standards that people use to evaluate their behavior or the consequences of their behavior as acceptable or unacceptable. Norms therefore help managers to organize management decisions by defining what behavior or conditions should be. In this study, normative approach in visitor management studies and the concept of norm, norm measurements and how they take place in visitor management are examined.

Keywords: Protected Areas, Visitor Management, Normative Theory, Standards, Norm Measurement

Ölçülmesi

\section{GİRIŞ}

Rekreasyon ve turizm amaçlı kullanılan korunan alanlarda (milli parklar, tabiat parkları ve diğer rekreatif-turistik mekânlar) ziyaretçi sayılarının sürekli artması ile birlikte, ziyaretçi faaliyetlerinin neden olduğu etkilerin tespit edilmesi ve yönetilmesi giderek zorlaşmaktadır. Bu durum alan yöneticilerinin karar verme süreçlerini de etkilemekte ve sürdürülebilir yönetimi karmaşık hale getirmektedir. Rekreasyonel faaliyetlerde bulunan kişiler, doğrudan veya dolaylı olarak başkalarının rekreasyon deneyimlerini etkileyebildikleri gibi aynı zamanda fiziksel çevreyi de doğrudan veya dolaylı olarak etkileyebilmektedirler. Bu noktada, ziyaretçi yönetimi çalışmaları ile kullanıcı deneyimlerinin rekreasyonel kalitesini arttırmanın yanı sıra olumsuz etkileri kontrol etmek amacıyla kalite göstergeleri ve standartları belirlenerek taşıma kapasitesi analizleri yapılmaktadır (Manning, 2007).

Taşıma kapasitesi analizlerini sistematik bir şekilde gerçekleştirebilmek ve oluşan olumsuz etkileri kontrol etmek ve alanı daha iyi yönetebilmek için geliştirilen çeşitli ziyaretçi yönetim modelleri vardır. Geliştirilen bu modeller; Rekreasyonel Fırsat Dağılımı (ROS) (Clark ve and Stankey, 1979), Kabul Edilebilir Değişim Sınırları (LAC) (Stankey ve ark. 1985), Ziyaretçi Etkinlikleri için Yönetim Süreci (VAMP) (Graham ve ark., 1988), Taşıma Kapasitesi Değerlendirme Süreci (CCAP) (Shelby ve Heberlein, 1984), Ziyaretçi Etki Yönetimi (VIM) (Graefe ve ark., 1990), Ziyaretçi Deneyimini ve Kaynağı Koruma (VERP) (Manning, 2001) olarak bilinmektedir. Bu modellerin uygulamalarında izlenilen aşamalar farklılık gösterse de 
ortak amaçları kaynak ve kullanıcı arasındaki koruma-kullanım dengesini sağlamak ve eş zamanlı olarak rekreasyon deneyim kalitesini arttırmaktır (Pigram ve Jenkins 1999).

Kaynak değerlerinin ve kullanım miktarındaki değişimlerin ziyaretçilerin rekreasyon deneyim kalitesini etkilediği bilinmektedir, ancak bu durum ziyaretçiler arasında farklılık göstermektedir. Yani tüm bireyler artan kullanıma ya da değişen kaynak değerlerine aynı derecede tolerans göstermemektedir. Bireylerin etkilere olan toleranslarını belirlemek zordur çünkü farklı bireyler, başkalarının varı̆̆ını değerlendirirken veya diğer kullanıcıların yarattığı etkileri değerlendirirken farklı normatif standartlar belirtmektedirler.

Normlar sosyal bilimler disiplinlerinde kullanılan kuramsal bir olgu olup, ziyaretçi yönetimi çalışmalarında kabul edilebilirlik sınırlarının ne olduğunu ve hangi etki düzeyine kadar kullanıma izin verilebileceğini açıklamada kullanılan bir kavramdır (Manning, 2018). Araştırmalarda normlar, belirli bir rekreasyon alanının sosyal, çevresel ya da yönetimsel özelliklerine karşı bireylerin ortak tutum ve tercihlerini kavramsallaştırmada kullanılmaktadır (Manning, 2007). Normların bu tarz araştırmalara entegre edilmesiyle, rekreasyon alanlarında ziyaretçi yönetimine aşağıda özetlenen gibi önemli katkılarının olduğu ortaya konmuştur (Shelby ve Vaske, 1991; Heywood, 1996; Shelby, Vaske ve Donnelly, 1996);

- İstenilen ideal koşulları belirlemeye yardımcı olmak,

- Göstergeleri yani ölçülebilir değişkenleri tanımlamak,

- Gösterge değişkenleri için standartları belirlemek,

- Kabul edilemez ile kabul edilebilir koşullar arasındaki farkı ortaya koymak,

- Normlar hakkında fikir birliği derecesini göstermek.

Uluslararası literatürde özellikle Kuzey Amerika'da yapılan araştırmalarda normatif yaklaşım çalışmalarının önemli etkileri olduğu kanıtlanmışken (örn: Donnelly, Vaske, Whittaker, ve Shelby, 2000; Manning, 2007, 2011; Shelby ve ark., 1996; Vaske, Donnelly, ve Shelby, 1992), ülkemizdeki ulusal literatürde ziyaretçi yönetimi konusunda yapılan çalışmalarda normatif yaklaşım araştırmaları az sayıdadır (örn: Akten ve Gül, 2014; Göktuğ ve Arpa, 2015; Akyol ve Akbulut, 2017).

Bu çalışmada, rekreasyon ve turizm amaçlı kullanılan korunan alanlarda kaynak değerlerini ve sosyal koşulları korumak için yapılan ziyaretçi yönetimi çalışmalarında yer alan normatif yaklaşım ve bu bağlamda, norm kavramı, normların nasıl ölçüldüğü ve ziyaretçi yönetiminde nasıl yer bulduğu incelenmiştir.

\section{NORMATÍF TEORİ}

Normlar "normal, ortalama, olağan veya standart" anlamına gelmektedir (Cancian, 1975). Normlar bir toplumda yaşayan insanların neyi, ne zaman ve nasıl yapmaları gerektiğini bildiren kurallardır. Her kültür kendi varlığını birlik ve beraberlik hâlinde ayakta tutmak için insan davranışlarını düzenlemek zorundadır. Bu süreçte normlar birer davranış rehberi olurlar (Güngör, 2011).

Normlar sadece toplumsal düzeyde insanların nasıl davranması gerektiğini belirlemede değil, aynı zamanda bireylerin toplumda nasıl davranmaları gerektiğini ifade etmek içinde kullanılmaktadır (Homans, 1950; Fishbein ve Ajzen, 1975). Bireyler eğer normları ihlal ederlerse, ne kazanıp kazanmayacaklarını yani davranışlarının doğuracağı sonuçları öngörebilmektedirler (McDonald, 1996). 


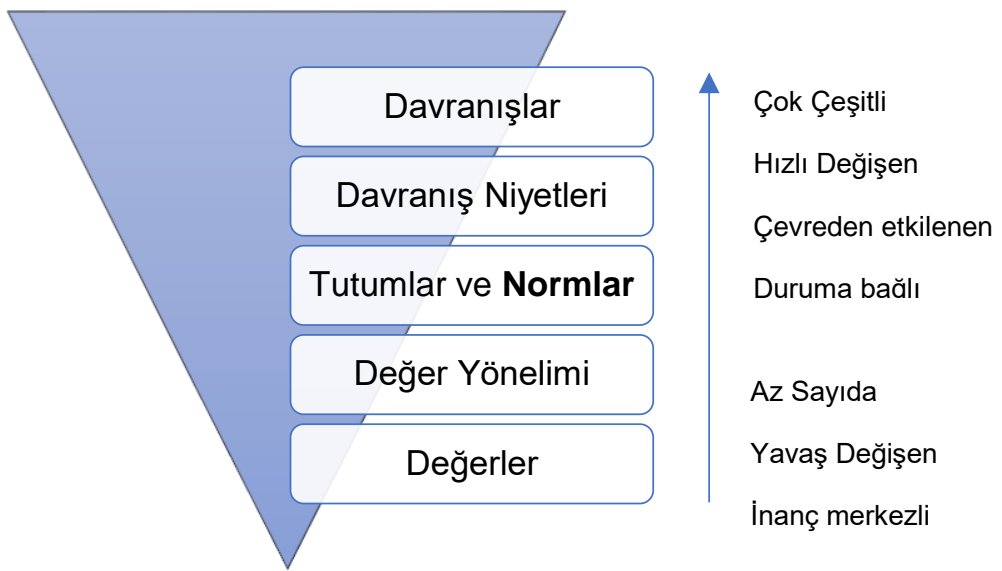

Şekil 1. İnsan Davranışının Kavramsal Hiyerarşi Modeli (Vaske ve Donnely, 1999).

Psikolojide normlar bireyin davranışlarının kavramsal süreçleri içerisinde açıklanmaktadır. Vaske and Donnelly (1999)'nin belirttiğine göre kavramsal hiyerarşi modelinde bireyin davranışları meydana gelene kadar değerlerden başlayan bir yapılanmanın olduğu görülmektedir. Bireyin değerleri az sayıda ve çok yavaş değişim göstermekte iken davranışları çok çeşitli ve hızlı değişim göstermektedir. Ayrıca araştırmacılar hiyerarşideki her seviyenin bir önceki veya bir sonraki seviyeye etkisi olduğunu belirtmişlerdir (Ball-Rokeach ve ark., 1984; Fulton ve ark., 1996; Homer ve Kahle, 1988; Rokeach, 1973;1979). Modelde normlar, tutumlar ile aynı seviyede ve orta kısımda yer bularak 'değerlendirici' olarak açıklanmıştır (Şekil 1).

Rekreasyon ve turizm alanında normlar, bireylerin faaliyetlerini, çevrelerini, yönetim eylemlerini veya koşullarını iyi veya kötü, kabul edilebilir veya edilemez olarak değerlendirmede kullandığı standartlar olarak tanımlanmaktadır (Shelby, Vaske ve Donnelly, 1996). Benzer şekilde Whitaker ve Shelby (2002), normları neyin uygun olup olmadığını değerlendirme ya da kişilerin meydana gelen davranış veya durumları değerlendirmede kullanılan standartlar olarak tanımlamıştır.

Bu araştırmalarda normlar yani normatif yaklaşım üç ana paradigma üzerinden açıklanmaktadır;

(1) norm odaklama ve aktivasyon modelleri

(2) gerekçeli (sebepli) eylem teorisi

(3) yapısal özellikler modelleri (Vaske ve Whitaker, 2004).

Norm odaklama ve aktivasyon modelleri, kişisel normların bireyin davranışlarını nasıl etkilediğini anlamak için kullanmaktadır. Bir davranışı etkilemek için kişisel normun belirgin olması gerekmektedir yani birey davranışının sonuçlarının ne olduğunu bilmeli ve kişisel eylemleri için sorumluluk sahibi olmalıdır (Cialdini ve ark. 1990).

Gerekçeli eylem teorisi; davranışın niyet tarafından belirlendiğini kabul etmektedir (Ajzen ve Fishbein, 1977). Ajzen ve Fishbein'e göre, niyet tutum ve öznel norm olmak üzere iki belirleyicinin fonksiyonu olarak görülmektedir. Öznel normlar bireyin başka bireyler için ne yapması gerektiğini düşündüğü davranışlar ile ilgilidir.

Yapısal özellikler modelleri ise sosyal normları tanımlamak için kullanılmaktadır. Sosyal normlar grup üyeleri tarafından paylaşılan standartları belirtmektedir (Vaske, Shelby, Graefe ve Heberlein, 1986). Standartları yani kabul edilen veya edilmeyeni belirttiğinden dolayı ziyaretçi yönetim modellerinde normlar bu paradigma üzerinden açıklanmaktadır. Kabul Edilebilir Değişim Sınırları (LAC), Ziyaretçi Etki Yönetimi (VIM) ve Ziyaretçi Deneyimini ve Kaynağı Koruma (VERP) gibi modellerde yer alan kabul edilebilir sosyal ve fiziksel koşullar için standartların belirlenmesi aşamasında sosyal normlar nicelik olarak bilgi sağladığı için etkili bir 
yaklaşımdır. Hardin (1968)'nin 'Ortak Kaynakların Paylaşımı Trajedisi'nde belirttiği gibi bireysel davranışlar kümülatiftir ve bir kaynağa önemli ölçüde zarar verebilmektedir. Bu doğrultuda, normların ortak kaynakların korunmasında dikkate alınmasının gerekliliği de açıkça görülmektedir.

\section{NORMLARIN ÖLÇÜLMESİ}

Literatürde Yapısal Özellikler Modelleri ile ilgili çalışmalar, J. Jackson (1965)'nın sosyolojideki rol teorisini anlamanın bir aracı olarak geliştirdiği, Geridönüş Potansiyel Modeli’ni temel almaktadır (Manning, 2018). Bir bireyin davranışlarında, başkalarının onayını veya onaylamamasını ölçmek için kurduğu bu modelde Jackson, rolleri "davranış için reçete" yani norm olarak kabul etmiştir. Model üzerinde $X$ ekseni davranış derecelerini, $Y$ ekseni ise onaylanma ve onaylamama derecelerini göstermektedir (Şekil 2). "Geri dönüş" terimi, diğerlerinin onaylama veya onaylamama seviyelerini ifade eder. "Potansiyel" terimi, grafik üzerindeki ölçümlerin gerçek değil, beklenen durum olduğunu ifade etmektedir. Grafik, bir sosyal grubun anket cevaplarından elde edilen ortalama değerler kullanılarak oluşturulmuştur. Ankete katılanlara değerlendirilecek bir dizi koşul verilmiş ve Jackson çalışmasında, katılımcılardan altı adet giderek artan otoriter işyeri davranışlarını değerlendirmelerini istemiştir ve katılımcılar her davranışa 9 puanlık ölçek üzerinden yüksek oranda onaylamıyorum seviyesinden başlayarak yüksek oranda onaylıyorum seviyesine kadar olan aralıkta bir değer vermişlerdir. Her davranış için cevapların ortalaması alınmış ve grafik üzerinde çizilmiştir. Ortalama değerleri gösteren noktalar bir eğri çizgisi ile birleştirilmiş ve böylece geri dönüş potansiyeli eğrisi oluşturmuştur. Bu eğriye norm eğrisi de denilmektedir (Manning ve ark.,1996). Normları tanımlamak için kullanılan Geridönüş Potansiyeli Modelinde eğrinin en yüksek noktası, anket uygulanan sosyal grubun iş yeri davranışları için ideal ya da en arzu edilen durumu belirtmektedir.

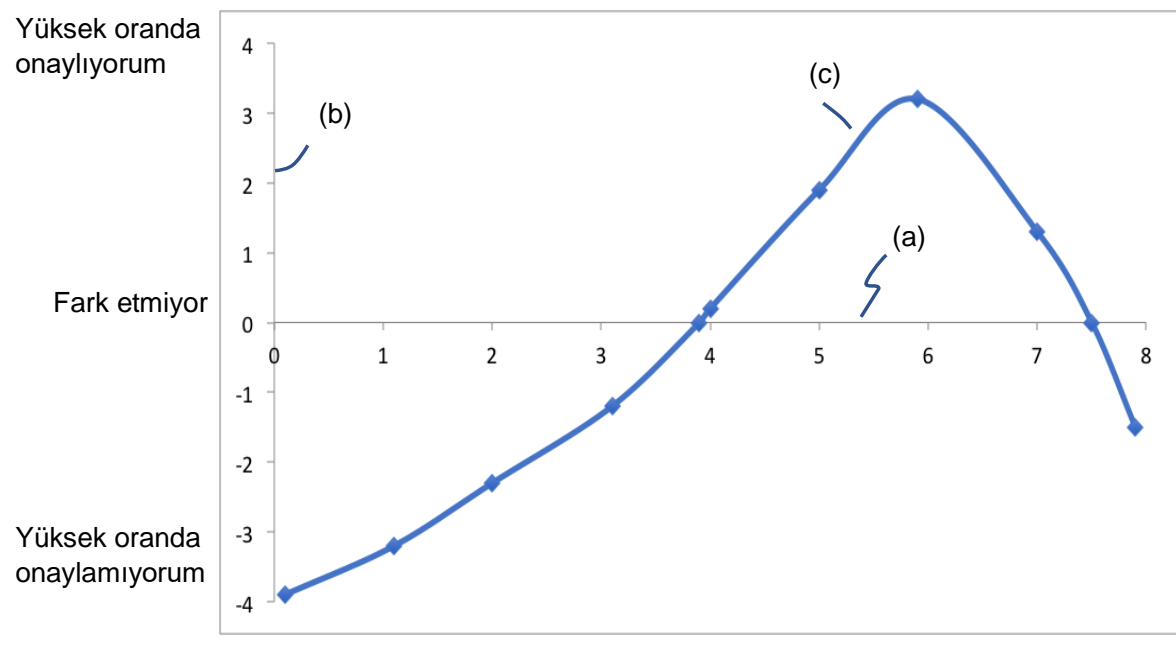

Şekil 2: Geridönüş Potansiyel Modeli (Jackson, 1965)

Jackson (1965)'a göre, bu nokta grup için normun tanımıdır. Ancak, tüm grafiğin bir norm olarak ele alınmasının daha yararlı olduğuna dikkat çekmektedir. Bu bakış açısına göre, araştırmacılar bir grup içinde hangi normların ne derecede var olduğunu belirleyebilmektedirler. Eğri aynı zamanda normun kabul edilebilir davranış aralığını, yoğunluk derecelerini ve kristalleşme yani grup üyeleri arasında her bir durumla ilgili anlaşma miktarını göstermektedir (Jackson, 1965).

Jackson (1965)'ın modeli, rekreasyon araştırmalarında kapsamlı bir şekilde uygulanmış ve özellikle de bir rekreasyon alanında kaç kişiye kadar olan sayının çok fazla olduğunu tanımlayan norm (standart) belirleme çalışmalarında kullanılmıştır (bkz. Donnelly, Vaske, Whittaker ve Shelby, 2000; Manning, Lawson, Newman, Laven ve Valliere, 2002; Shelby ve ark., 1996, Vaske ve Donnelly, 2002). Diğer farklı uygulamalar ise, kamp alanı veya cazibe merkezi gibi ortak kullanılan alanlarda (Heberlein ve Dunwiddie, 1979; Shelby, 1981, Manning, Lime, Freimund ve Pitt, 1996); balık tutma faaliyet alanlarında (Martinson ve Shelby, 1992; Whittaker ve Shelby, 1993); yaban hayatı gözlem platformlarında (Whittaker, 1997); kamp 
alanlarındaki sert zeminin ve kamp ateşi yerlerinin belirlenmesinde (Shelby, Vaske ve Harris, 1988); yaban hayatı ile ilgili yönetim faaliyetleri uygulamalarının kabul edilebilirliği çalışmalarında (Wittmann, Vaske, Manfredo ve Zinn, 1998; Zinn, Manfredo, Vaske ve Wittmann, 1998) ve orman yangını politikaları çalışmalarında (Kneeshaw, Vaske, Bright ve Absher, 2004) uygulanmıştır. Tüm bu uygulamalarda, araştırmacılar ya kabul edilebilir davranışları ya da davranıştan kaynaklanan kabul edilebilir durumları araştırmışlardır (Vaske, Donnelly ve Whittaker, 2000). Böylelikle yapısal özellikler modeli ile ziyaretçiler, yöneticilerin standartları belirlemek için kullanabilecekleri sosyal normlarını tanımlayan kişisel normlarını belirtmektedir. Bu standartlar, kabul edilemez etkilere yol açan davranışları kısıtlamak için yönetimsel müdehalelerin ne zaman gerekli olduğunu göstermektedir.

Normatif çalışmalarda kullanıcıların değerlendirmelerini yani normlarını belirtmeleri için farklı ölçme yöntemleri kullanılmaktadır (Donnelly, Vaske ve Shelby, 1992). Kullanılan metotlardan biri değerlendirme ölçekleridir ve yapılan çalışmalarda 'tercih edilen - tercih edilmeyen' (Martinson ve Shelby, 1992; Shelby ve Harris, 1985); 'hoş olan - hoş olmayan' (Vaske, Shelby, Graefe ve Heberlein, 1986); 'memnun edilmiş - memnun edilmemiş' (Heberlein ve Vaske 1977); 'olumlu - olumsuz' (Vaske ve ark., 1986); 'istenen - istenmeyen' (Hammitt ve Rutlin, 1995; Martin, McCool ve Lucas, 1989) veya en yaygın karşılaşılan ölçek olan 'kabul edilebilir kabul edilemez' (Freimund, Vaske, Donnelly ve Miller, 2002; Manning, Lawson, Newman, Laven, ve Valliere, 2002; Manning, Lime, Freimund, ve Pitt, 1996; Shelby ve Shindler, 1992) gibi farklı değerlendirme ölçekleri kullanılmıştır (Şekil 3).

\begin{tabular}{|r|l|l|l|l|l|}
\hline $\begin{array}{l}\text { Karşılaştığınız kişi } \\
\text { sayısı sizi nasıl } \\
\text { hissettirir? }\end{array}$ & $\begin{array}{c}\text { Çok } \\
\text { memnun }\end{array}$ & Memnun & $\begin{array}{c}\text { Benim için } \\
\text { önemli } \\
\text { değil }\end{array}$ & $\begin{array}{c}\text { Memnun } \\
\text { değil }\end{array}$ & $\begin{array}{c}\text { Hiç } \\
\text { Memnun } \\
\text { değil }\end{array}$ \\
\hline $\mathbf{1}$ kişi görmek & & & & & \\
\hline $\mathbf{5}$ kişi görmek & & & & & \\
\hline $\mathbf{1 0}$ kişi görmek & & & & & \\
\hline $\mathbf{1 5}$ kişi görmek & & & & & \\
\hline $\mathbf{2 0}$ kişi görmek & & & & & \\
\hline $\mathbf{3 0}$ kişi görmek & & & & & \\
\hline
\end{tabular}

Şekil 3: Değerlendirme Ölçeği Örneği

Kullanılan başka bir metot ise açık ve kapalı uçlu sorular sormaktır. Kapalı uçlu sorular 'Kaç kişiye kadar tolerans gösterebilirsiniz? sorusuna verilen cevap seçeneklerinden birinin işaretlenmesi ile veya açık uçlu soru olarak cevaben boşluk doldurmaları istenerek ölçülebilmektedir (Hall ve Roggenbuck, 2002; Manning ve ark., 2002) (Şekil 4). Bazı çalışmalarda ise kullanıcıya verilen açık ve kapalı cevap seçenekleri dışında 'etrafımdaki kişi sayısı beni etkiliyor ama sayı belirtemem', 'ilgilenmiyorum' gibi ek seçenekler de sunulmaktadır (Donnelly ve ark., 1992; Roggenbuck ve ark., 1991). Bu özellikle, katılımcıların, etkilerini kabul ya da toleranslarını temsil eden kesin rakamları belirtmekte güçlük çekebilecekleri yüksek kullanım oranına sahip alanlarda yapılan çalışmalarda kullanılan seçenektir (Şekil 5). Açık ve kapalı uçlu sorular yukarıda verildiği gibi rakamsal formatta cevap seçenekleriyle kullanılabildiği gibi görsel ölçme yöntemleri kullanılarak da değerlendirilebilmektedir.

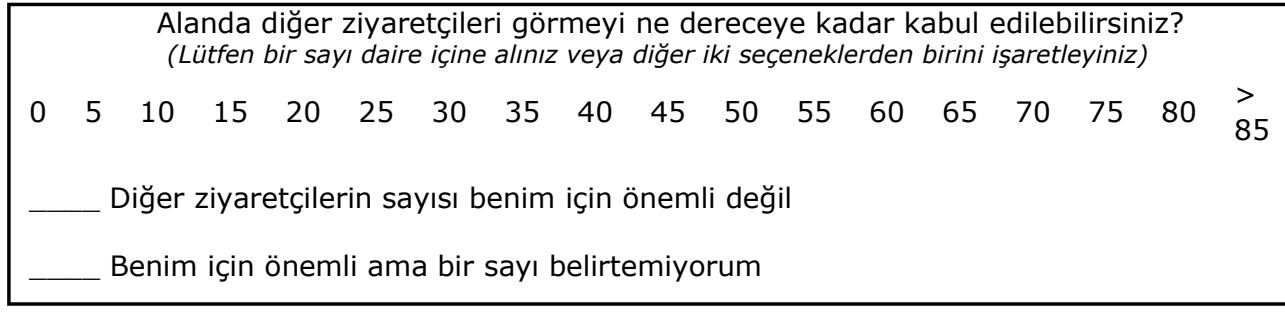


Şekil 4: Kapalı Uçlu Soru Örneği

Alanda etrafınızda kabul edilebilir ziyaretçi sayısı nedir?
(Lütfen boş/uğu doldurunuz ya da diğer iki seçenekten birini işaretleyiniz)
kadar ziyaretçi görmeyi kabul edebilirim
Benim için önemli değil
Benim için önemli, fakat herhangi bir sayı veremem

Şekil 5: Açık Uçlu Soru Örneği

Normları ölçmek için kullanılan bu farklı yöntemlerin farklı sonuçlar ortaya çıkarabileceği yapılan araştırmalarda görülmektedir (Manning ve ark., 1999). Örneğin, açık uçlu soru formatı görsel ölçme yöntemleriyle kullanıldığında, kapalı uçlu soru formatından daha düşük sonuçlar elde edilmesine neden olabilir ya da görsel tekniklerle ölçülen norm bildirimlerinin, özellikle yüksek kullanımın olduğu alanlarda, rakamsal formata göre daha yüksek sonuçlar elde edilebilir. Belirtilen bu farklı ölçme yöntemlerinden biri diğerinden daha geçerli yöntemdir denemez, ancak araştırmacılar ve yöneticiler bu ölçme tekniklerinin etkilerinin bilincinde olmalı ve çalışma bulgularını yorumlamada ve uygulamada dikkat ve özen göstermelidir.

\section{ZİYARETÇİ YÖNETİMİNDE NORMATİF TEORİ}

Korunan doğal alanlarda kaynakların bütünlüğünün çeşitli rekreasyonel faaliyetler sonucu bozulduğunu ispatlayan çalışmalar biyologlar ve ekologlar tarafından, (bkz. Boyle ve Samson, 1985; Hammitt ve Cole, 1987; Knight ve Gutzwiller, 1995; Kuss, Graefe, ve Vaske, 1990) ziyaretçilerin birbirlerinin rekreasyon deneyimleri üzerinde etkileri olduğu gösteren çalışmalar da sosyal bilimciler tarafından ortaya konmuştur (bkz. Kuss ve ark., 1990; Manning, 1986; Shelby ve Heberlein, 1986).

Ziyaretçi yönetimi ile korunan alanlarda rekreatif kullanımlardan dolayı ortaya çıkan olumsuz etkilerin veya problemlerin üstesinden gelmek için bir yol haritası çıkartılması istenirken, sorunları belirleme, anlama ve analiz etmeye yardımcı olan bilgileri toplama, düzenleme ve değerlendirmede de normlar, teorik bir çerçeve sağlamaktadır. Çünkü bu alanlarda rekreasyonel faaliyetlerin etkilerinin bilinmesi ve değerlendirilmesi ile birlikte gerekli önlemlerin alınarak daha rasyonel yönetim planlamalarının hazırlanması korunan alanların sürdürülebilirliği açısından önemlidir.

Ziyaretçi yönetim modellerinin planlama sürecinde, alanda olması istenen biyolojik ve sosyal koşulların negatif bir etkiye neden olmaksızın kullanılabilmesi için kapasite belirleme çalışmaları önemli bir yere sahiptir. Taşıma kapasitesi belirlenirken genellikle tanımlayıcı ve değerlendirici unsurlar dikkate alınmaktadır (Coccossis ve Mexa, 2002). Tanımlayıcı unsurlar, alan kaynaklarına veya ziyaretçinin deneyimlerine yönelik etkilerin belirlenmesini ifade etmektedir. Örneğin, ziyaretçinin rekreasyonel faaliyetleri sırasında diğer kullanıcılarla karşılaşma durumu ya da rekreasyon alanında yere çöp atma oranı gibi çeşitli etkilerin niteliğinin, kapsamının ve yerinin tespit edilmesi çalışmalarını kapsamaktadır. Değerlendirme unsurları ise, gösterge olarak ifade edilen, göze çarpan etkilerin yani tanımlayıcı unsurların seçilmesini ve bu göstergelerin kabul edilebilir etki seviyelerini belirlemek için standartların belirlenmesini kapsamaktadır (Hall ve ark. 1996). Değerlendirme unsurları farklı kaynaklardan elde edilen bilgilerle saptanabilir. Örneğin, yönetimdeki karar mercileri kendi fikir ve değerlerine dayanarak standartları belirleyebilirler veya uzman kişilerin görüş ve önerilerine başvurarak çalışmaları birlikte yürütebilirler (Manfredo, Vaske ve Decker,1995). Ayrıca ilgi gruplarının ve kullanıcıların değerlendirmelerini de göz önüne alarak standartları belirleyebilirler (Vaske, 1977). Bunların dışında toplumun genel değerlendirmelerini de dikkate alarak kaynak için en doğru kararlar alınabilir (Shelby ve ark., 1996).

Standartların belirlenmesinde kullanıcı sayısı, kullanıcıların gerçekleştirdikleri aktivite tipleri, bu aktivitelere nerede katıldıkları, kullanımlarının etkileri gibi konular eylem planlarına doğrudan ya da dolaylı katkı sağlayan yardımcı unsurlardır. (Shelby ve Vaske, 1991).

Standartlar, kabul edilebilir koşulları tanımlayan ölçülebilen sayısal değerlerdir ve yönetimin odak noktasını, geniş ve niteliksel ifadelerden, karar verme için bir temel teşkil eden, daha 
spesifik, istenen koşulları belirten ifadelere daraltır. Vaske ve arkadaşları (2002) standartların, arzu edilen koşulları (örneğin, çöpün olmaması gibi) ve yöneticilerin sınırlarını aşmak istemediği koşulları (örneğin, başka insanlarla karşılaşma, insan-yaban hayatı çatışması gibi) belirlediğini ifade etmiştirler.

\section{SONUÇ VE ÖNERÍLER}

Rekreasyonel ve turizm amaçlı kullanılan korunan alanlarda, artış gösteren kullanımların kaynakların bütünlüğüne ve kullanıcıların rekreasyon deneyimlerine tehdit oluşturduğu bilinmektedir (Manning, 2014). Normlar "ne olmalıdır" diye tanımlandıkları için güçlüdür ve bundan dolayı, kaynak ve ziyaretçi yönetiminde çevresel, sosyal ve yönetimsel koşulları değerlendirmek için kullanılırlar.

Ziyaretçi yönetimi çalışmalarında en çelişkili kısım, standartların formüle edilmesidir çünkü standartlar, kabul edilebilirlik sınırını belirlemektedir. Standartların formülleştirilmesinde ise normatif teori ve ilgili deneyimsel metotlar kullanılmaktadır. Uluslararası birçok araştırmacı normatif teori ve metotlarını bu amaç için kullanmıştır (örn: Heberlein, Vaske, 1977, Vaske, Graefe, Shelby ve Heberlein. 1986, Shelby ve Heberlein, 1986, Shelby, Vaske ve Donnelly, 1996, Vaske, Donnelly ve Shelby, 1992; 1993, Manning, 2007).

Ülkemizde rekreasyon ve turizm amaçlı kullanılan korunan alanlardaki ziyaretçi yönetimini çalışmaları uluslararası çalışmalarla karşılaştırıldığında henüz istenilen düzeyde değildir ancak ulusal literatürdeki araştırmalar sürdürülebilir yönetim için bu çalışmaların önemini ve gerekliliğini ortaya koymaktadır (örn: Gündüz ve Akpınar, 2002; Sayan ve ark., 2005; Akten ve ark., 2012; Göktuğ ve Kurkut, 2016).

Korunan alanlarda ziyaretçi yönetimi bağlamında; Göktuğ ve Arpa (2015)'nın Ilgaz Dağı Milli Parkı'nda normatif yaklaşımla rekreasyon deneyim kalitesinin saptanmasıyla ilgili yaptıkları çalışma ve Akten ve Gül (2014)'ün Gölcük Tabiat Parkı'nda standartların belirlenmesi çalışması iyi birer örnek olmaktadır. Milli parklar ve tabiat parkları gibi yoğun kullanıcı baskısı altında olan alanların yönetim planları, ziyaretçi yönetimi çalışmaları normatif yaklaşımla standart belirlemeleri yapılarak revize edilmelidir.

Sadece milli parklar ve tabiat parkları gibi korunan alanlarda değil, tarihi ve kültürel değerleri bakımından koruma altında olup yoğun ziyaretçi baskısı altında olan örenyerlerinde de ziyaretçi yönetimi çalışmaları yapılmaktadır. Örneğin, son yıllarda Göbeklitepe Örenyeri ziyaretçi yönetimi çalışmaları devam etmektedir ve bu gibi çalışmaların yasal çerçevelerle desteklenerek korunan alanların sürdürülebilir yönetimi gereklidir.

\section{KAYNAKLAR}

Akten, S., Gül, A., Akten, M. (2012). Korunan doğal alanlarda kullanılabilecek ziyaretçi yönetim modelleri ve karşılaştırılması. SDÜ Orman Fakuiltesi Dergisi, 13 (1): 57-65.

Akten, S., Gül, A. (2014). Korunan doğal alanlarda ziyaretçilerin olası etki düzeyleri önlem ve standartların belirlenmesi (Gölcük Tabiat Parkı örneği). SDÜ Orman Fakültesi Dergisi / SDU Faculty of Forestry Journal, 15: 130-139.

Akyol, A., Akbulut, E. (2017). Korunan alanların planlanması ve etkin yönetiminde ziyaretçi özellikleri ve algılarının önemi: Kurşunlu Şelalesi Tabiat Parkı örneği. Türkiye Ormancılık Dergisi, 18(3): 197-206.

Ajzen, I., Fishbein, M. (1977). Attitude-behavior relations: A theoretical analysis and review of empirical research. Psychological Bulletin, 84(5), 888-918.

Ball-Rokeach, S. J., Rokeach, M, Grube, J. W. (1984). The great American values test: Infuencing behavior and belief through television. New York: Free Press.

Boyle, S. A., Samson, F. B. (1985). Effects of non-consumptive recreation on wildlife: A review. Wildlife Society Bulletin, 13, 110-116.

Cancian, F. (1975). What are norms? A study of beliefs and actions in a Maya community. New York: Cambridge University Press. 
Clark, R.N., Stankey, S. (1979). The recreation opportunity spectrum: a framework for planning, management and research. Gen. Tech. Rep. PNW-GTR-098. Portland, OR: U.S. Department of Agriculture, Forest Service, Pacific Northwest Research Station. 32 p.

Cialdini, M. P. Reno, R. R. Kallgren, C. A. (1990). A focus theory of normative conduct: Recycling the concept of norms to reduce littering in public places. Journal of Personality and Social Psychology. 58, 1015-1026.

Coccossis, H., A. Mexa, (2002). Defining, measuring and evaluating carrying capacity in european tourism destinations material for a aocument. Environmental Planning Laboratory of the University of the Aegean Department of Environmental Studies, Athens, Greece, No. B4-3040/2000/294577/MAR/D2, 113.

Donnelly, M. P., Vaske, J. J., Shelby, B. (1992). Measuring backcountry standards in visitor surveys. In B. Shelby, G. Stankey, \& B. Shindler (Eds.), Defining wilderness quality: The role of standards in wilderness management-A Workshop Proceedings (General Technical Report PNW-GTR-305, pp. 38-52). Portland, OR: USDA Forest Service.

Donnelly, M. P., Vaske, J. J., Whittaker, D., Shelby, B. (2000). Toward an understanding of norm prevalence: A comparative-analysis of 20 years of research. Environmental Management, 25, 403-414.

Fishbein, M., Ajzen, I. (1975). Belief, attitude, intention and behavior: An introduction to theory and research. Reading, MA: Addison-Wesley.

Freimund, W. A., Vaske, J. J., Donnelly, M. P., Miller, T. (2002). Using video surveys to access dispersed backcountry visitors' norms. Leisure Sciences, 24, 349-362.

Fulton, D. C., Manfredo, M. J., Lipscomb. J. (1996). Wildlife value orientations: A conceptual and measurement approach. Human Dimensions of Wildlife 1:24- 47.

Graefe, A.R., Kuss, F.R, Vaske, J.J. (1990). Visitor Impact Management:The Planning Framework. National Parks and Conservation Association, Washington, DC,156 p.

Graham, R., Nilsen, P., Payne, R. J. (1988). Visitor management in Canadian National Parks. Tourism Management, 9(1), 44-61.

Gündüz, S., Akpınar, N. (2002). Koruma-kullanım ilkeleri çerçevesinde Beynam Muhafaza Ormanı'nın rekreasyonel taşıma kapasitesinin saptanması üzerinde bir araştırma. Tarim Bilimleri Dergisi, 8(4), 344-351.

Güngör, E. (2011). Kültür Değismesi ve Milliyetçilik. İstanbul: Ötüken Yayınları.

Göktuğ, T. H., Arpa, N.Y. (2015). Ziyaretçi yönetimi bağlamında ılgaz dağı milli parkı'nda rekreasyon deneyim kalitesinin saptanması. Kastamonu Üni. Orman Fakuiltesi Dergisi, 15 (1) $146-161$.

Göktuğ, T. H., Kurkut, G. (2016). Korunan alanlarda sürdürülebilir ziyaretçi yönetimi stratejiler ve araçların incelenmesi. Bartın Üniversitesi Orman Fakültesi Dergisi, 18: 1, 118-131.

Hardin, G. (1968). The tragedy of the commons. Science, New Series, Vol. 162, No. 3859 (Dec. 13, 1968), pp. 1243-1248.

Hall, T.E., Shelby, B., Rolloff, D. (1996). Effect of varied question format on boaters' norms. Leisure Sciences, 18, 193-204.

Hall, T. E., Roggenbuck, J.W. (2002). Response format effects in questions about norms: Implications for the reliability and validity of the normative approach. Leisure Sciences, 24, 325-337.

Hammitt, W. E., Cole, D. N. (1987). Wildland recreation: Ecology and management. New York: John Wiley \& Sons.

Hammitt, W. E., Rutlin, W. M. (1995). Use Encounter Standards and Curves for Achieved Privacy in Wilderness. Leisure Sciences Volume 17. pp. 245-262.

Heywood, J. (1996). Social regularities in outdoor recreation. Leisure Sciences 18: 23-37. 
Heberlein, T. A., J. J. Vaske. (1977). Crowding and visitor conflict on the Bois Brule River. Technical Report WIS WRC 77- 04. Madison, WI: University of Wisconsin, Water Resources Center.

Heberlein, T. A., Dunwiddie, P. (1979). Systematic observations of use levels, campsites selection and visitor characteristics at High Mountain Lake. Journal of Leisure Research, 11, 307-316.

Homans, G.C. (1950). The human group. New York: Brace and World.

Homer, P. M., Kahle. L. R. (1988). A structural equation test of the value-attitude- behaveior hierarchy. Journal of Personality and Social Psychology 54:638- 646.

Jackson, J. M. (1965). Structural characteristics of norms. In I.D. Steiner \& M. F. Fishbein (Eds.), Current studies in social psychology (pp. 301-309). New York, NY: Holt, Rinehart, and Winston.

Kneeshaw, K., Vaske, J. Bright A. D. Absher, J. D. (2004). Situational Influences of Acceptable Wildland Fire Management Actions, Society \& Natural Resources, 17:6, 477-489.

Kuss, F. R., Graefe, A. R., Vaske, J. J. (1990). Recreation impacts and carrying capacity: A review and synthesis of ecological and social research. Washington, DC: National Parks and Conservation Association.

Knight, R. L., Gutzwiller, K. J. (Eds.). (1995). Wildlife and recreationists: coexistence through management and research. Washington, D.C.: Island Press.

Manfredo, M. J., Vaske, J. J., Decker, D. J. (1995). Human dimensions of wildlife management: Basic concepts (pp. 17-31). In R. Knight \& K. Gutzwiller (Eds.), Wildlife and Recreationists: Coexistence Through Management and Research. Washington, DC: Island Press.

Martin, S. R., McCool, S. F., Lucas, R. C. (1989). Wilderness Campsite Impacts: Do Managers and Visitors See Them the Same? Environmental Management Vol. 13, No. 5, pp. 623-629.

Manning, R. E. (1986). Studies in outdoor recreation. Corvallis, OR: Oregon State University Press.

Manning, R. E., Lime, D. W., Freimund, W. A., Pitt, D. G. (1996). Crowding norms at frontcountry sites: A visual approach to setting standards of quality. Leisure Sciences, 18, 39-59.

Manning, R., Lawson, S., Frymier, L. (1999). Navigating the confluence of two streams of social research: Contingent valuation and normative standards. Human Ecology Review, 6(1), 3548.

Manning, R. E., (2001). Visitor experience and resource protection: a framework for managing the carrying capacity of national parks. Journal of Park and Recreation Administration 19: 93-108.

Manning, R. E., Lawson, S., Newman, P., Laven, D., Valliere, W. (2002). Methodological issues in measuring crowding-related norms in outdoor recreation. Leisure Sciences, 24, 339348. Manning, R., W. Valliere, B. Wang, C. Jacobi. 1999. Crowding norms: Alternative measurement approaches. Leisure Sciences, 21, 97-115.

Manning, R. E. (2007). Parks and carrying capacity: Commons without tragedy. Washington,DC: Island Press.

Manning, R. E. (2011). Studies in outdoor recreation: Search and research for satisfaction (3rd ed.). Corvallis, OR: Oregon State University Press.

Manning, R.E. (2014). Research to guide management of outdoor recreation and tourism in parks and protected areas, Koedoe 56(2), 7.

Manning, R. E. (2018). Application of normative theory and methods in recreation and tourism. Book Chapter 25: Handbook of Research Methods for Tourism and Hospitality Management: Handbooks of Research Methods in Management series. Massachusetts, USA. Edward Elgar Publishing, Inc. 
Martinson, K. S., Shelby, B. (1992). Encounter and proximity norms for salmon anglers in California and New Zealand. North American Journal of Fisheries Management, 12, 559567.

McDonald, C. (1996). Normative perspectives on outdoor recreation behavior: Introductory comments. Leisure Sciences, 18 (1): 1-6.

Pigram, J. J., Jenkins, J. M. (1999). Outdoor recreation management, Routledge, London.

Roggenbuck, J., Williams, D. R., Bange, S. P., Dean, D. J. (1991). River float trip encounter norms: Questioning the use of the social norms concept. Journal of Leisure Research, 23, 133-153.

Rokeach, M. (1973). The nature of human values. New York : Free Press.

Rokeach, M. (1979). Understanding human values. New York : Free Press.

Sayan, M.S., Ortaçeşme, V., Karagüzel, O., Atik, M., Şahin, T., Yıldırım, E., Avcı, Ü. (2005). Termessos (Güllükdağ) Milli Parkı'nda Rekreasyonel Taşıma Kapasitesinin Belirlenmesi. TÜBİTAK Proje no: TOGTAG- 3197, 63s, Antalya.

Stankey, G., Cole, D., Lucas, R., Peterson, M., Frissell, S. (1985). The Limits of Acceptable Change (LAC) System for Wilderness Planning. USDA, GTR, INT-176 p.

Shelby, B. (1981). Encounter norms in backcountry settings: Studies of three rivers. Journal of Leisure Research, 13, 129-138.

Shelby, B., Heberlein, T. (1984). A conceptual framework for carrying capacity cetermination. Leisure Sciences. 6: 433-451.

Shelby, B., Harris, R. (1985). Comparing methods for determining visitor evaluations of ecological impacts: site visits, photographs, and written descriptions. Journal of Leisure Research, 17:1, 57-67.

Shelby, B., Heberlein, T. A. (1986). Social carrying capacity in recreation settings. Corvallis, OR: Oregon State University Press. OR: Oregon State University Press.

Shelby, B., Shindler, B. (1992). Interest group standards for ecological impacts at wilderness campsites. Leisure Sciences, 14, 17-27.

Shelby, B., Vaske, J. J., Harris, R. (1988). User standards for ecological impacts at wilderness campsites. Journal of Leisure Research, 20, 245-256.

Shelby, B., Vaske, J. J. (1991). Using normative data to develop evaluative standards for resource management: A comment on three recent papers. Journal of Leisure Research, 23, 173-187.

Shelby, B., Vaske, J. J., Donnelly, M. P. (1996). Norms, standards, and natural resources. Leisure Sciences, 18, 103-123.

Vaske, J. J. (1977). The relationship between personal norms, social norms and reported contacts in Brule River visitors perception of crowding. Masters Thesis. University of Wisconsin, Madison.

Vaske, J. J., Shelby, B., Graefe, A. R., Heberlein, T. A. (1986). Backcountry encounter norms: Theory, method and empirical evidence. Journal of Leisure Research, 18, 137-153.

Vaske, J. J., Donnelly, M. P., Shelby, B. (1992). Establishing management standards: Selected examples of the normative approach. Environmental Management, 17(5), 629-643.

Vaske, J. J., Donnelly, M. P. (1999). A value-attitude-behavior model predicting wildland preservation voting intentions. Society \& Natural Resources, 12: 523- 537.

Vaske, J. J., Donnelly, M. P., Whittaker, D. (2000). Tourism, national parks and impact management. In R. Butler \& S. Boyd (Eds.), Tourism and National Parks: Issues and Implications (pp. 203- 222). New York: John Wiley and Sons.

Vaske, J. J., Donnelly, M. P. (2002). Generalizing the encounter - norm - crowding relationship. Leisure Sciences, 24, 255-269. 
Vaske, J., Whittaker, D. (2004). Normative approaches to natural resources. In M.Manfredo, J. Vaske, B. Bruyere, D. Field, \& P. Brown (Eds.), Society and natural resources: A summary of knowledge (pp.283-294). Jefferson, MO: Modern Litho.

Wittmann, K., Vaske, J. J., Manfredo, M. J., Zinn,H. C. (1998). Standards for lethal response to probşem urban wildlife. Human Dimensions of Wildlife, 3(4), 29-48.

Whittaker, D., Shelby, B. (1993). Kenai River carrying capacity study: Important conclusions and implications. Report to Alaska State Parks. Anchorage, AK: National Park Service, RTCA project report.

Whittaker, D. (1997). Capacity norms on bear viewing platforms. Human Dimensions of Wildlife, 2, 37-49.

Whittaker, D., Shelby, B. (2002). Evaluating instream flows for recreation: Applying the structural norm approach. Leisure Sciences, 24, 363-374.

Zinn,H. C., Manfredo, M. J., Vaske, J. J., Wittmann, K. (1998). Using normative beliefs to determine the acceptability of wildlife management actions. Society \& Natural Resources, $11: 649-662$.

\section{EXTENDED ABSTRACT}

In protected areas, it is becoming more difficult to identify and manage the impacts of visitor activities due to a constantly increasing number of visitors. This also affects the decisionmaking process of land managers and complicates sustainable management. Visitors recreational activities can directly or indirectly affect other visitor's recreational experiences, as well as affect the physical environment. At this point, through visitor management studies carrying capacity analyses are carried out by determining quality of indicators and standards in order to control the negative impacts and to improve the recreational quality of user experiences.

There are several visitor management frameworks developed systematically to perform carrying capacity analyses. These models; Recreational Opportunity Spectrum (ROS), Limits of Acceptable Change (LAC), Carrying Capacity Assessment Process (C-CAP), Visitor Impact Management (VIM), Visitor Experience and Resource Protection (VERP). The common goal of these frameworks is to maintain the balance of protection and use between the source and the user and simultaneously to improve the quality of recreation experience.

Norms are a theoretical phenomenon used in social sciences disciplines. Norm is defined as "normal, average, ordinary or standard"(Cancian, 1975). Norms are rules that tell people living in a society what to do, when and how to do it. Every culture has to regulate human behavior in order to sustain its existence in unity and togetherness. In this process, norms become a guide to behavior (Güngör, 2011).

In natural resource management, norms are used to explain what the limits of acceptability and what level of impact can be allowed to use. Norms are also used to conceptualize the common attitudes and preferences of individuals against the social, environmental or managerial characteristics of a particular recreation area (Manning, 2007). By integrating norm studies into such research, it has been demonstrated that they have made significant contributions to visitor management in recreation areas as outlined (Shelby and Vaske, 1991; Heywood, 1996; Shelby, Vaske and Donnelly, 1996); (1) to help determine the desired ideal conditions, (2) identify indicators, (3) setting standards for indicator variables, (4) to reveal the difference between unacceptable and acceptable conditions, and (5) to show the degree of consensus about norms.

There are different measurement methods are used to indicate users' assessments, i.e. norms (Donnelly, Vaske and Shelby, 1992). One of the methods used is evaluation scales and the 'preferred - not preferred' (Martinson and Shelby, 1992; Shelby and Harris, 1985); 'pleasantunpleasant' (Vaske, Shelby, Graefe and Heberlein, 1986); 'satisfied - dissatisfied' (Heberlein and Vaske 1977); 'positive - negative' (Vaske et al., 1986); 'desired - undesirable' (Hammitt and Rutlin, 1995; Martin, McCool and Lucas, 1989) or the most common scale is 'acceptable - unacceptable' (Freimund, Vaske, Donnelly and Miller, 2002; Manning, Lawson, Newman, 
Laven, and Valliere, 2002; Manning, Lime, Freimund, and Pitt, 1996; Shelby and Shindler, 1992). Another method used is to ask open and closed-ended questions. Closed-ended questions can be measured by marking one of the answer options given to the question 'How many people can you tolerate? or by asking them to fill in the blank in response to an openended question (Hall and Roggenbuck, 2002; Manning et al., 2002). In some studies, additional options such as 'the number of people around me affect me but i can't specify numbers', 'I'm not interested' except for the open and closed answer options given to the user (Donnelly et al., 1992; Roggenbuck et al., 1991). Open and closed-ended questions can be used with answer options in numerical format as well as using visual measurement methods.

Protected areas, especially areas used for recreational and tourism purposes are threaten by increased uses. Norms are strong because they are defined as "what should be" therefore, they are used to assess environmental, social and managerial conditions in resource and visitor management. The most contradictory part of visitor management studies is the formulation of standards because standards set the limit of acceptability. Normative theory and related experiential methods are used in the formulation of standards. Many international researchers have used their normative theories and methods for this purpose. 